\title{
Teletandem: Possibilidades, dificuldades e abrangência de um projeto de comunicação on-line de PLE
}

\author{
João Antonio TELLES \\ Universidade Paulista Júlio de Mesquista Filho - Assis \\ tellesjoao@uol.com.br \\ Michael J. FERREIRA ${ }^{2}$ \\ Georgetown University \\ mjf62@georgetown.edu
}

\section{Resumo}

Este artigo inicia-se com a apresentação dos objetivos de um projeto internacional que utiliza o teletandem em um contexto virtual, colaborativo e autônomo para a comunicação intercultural e multimodal em Português - Língua Estrangeira (PLE). Em seguida, analisamos os dados estatísticos oferecidos pelo site do projeto, tentando oferecer algumas inferências que mostram a relação entre as possibilidades, as dificuldades e, acima de tudo, a abrangência de um projeto que visa à promoção do interesse e da aprendizagem de PLE em vários países. Os resultados da análise mostram: (a) a importância de um site para divulgação e expansão do aprendizado de PLE com um baixo custo; (b) diferentes níveis de interesse de certos países em PLE; (c) a importância do estabelecimento e da manutenção de contatos com departamentos de PLE de algumas universidades com o intuito de expandir o ensino e a aprendizagem de PLE; $\mathrm{e}$ (d) a importância de vários procedimentos de gerenciamento para manter o contato e $\mathrm{o}$ interesse desses departamentos para projetos de colaboração on-line com o Brasil.

Palavras-chave: Teletandem; PLE; interação síncrona on-line.

1 Professor Doutor e Livre-Docente do Centro de Línguas e Desenvolvimento de Professores; pesquisador bolsista FAPESP - Fundação de Amparo à Pesquisa do Estado de São Paulo.

2 Professor Doutor e Livre Docente do Department of Spanish and Portuguese. 


\begin{abstract}
This article begins with a brief overview of the objectives of an international project that uses teletandem as a virtual, collaborative and autonomous context for on-line intercultural and multimodal communication in Portuguese as a Foreign Language (PFL). We, then, move on to analyze the statistical data supplied by the site of the project, attempting to draw on a few inferences that can show the interconnection of the possibilities, difficulties and, above all, the scope of the project that promotes the interest and learning of PFL in various countries. The result of our analysis showed (a) the importance of a site for divulging and expanding the learning of PFL with relative low financial investment; (b) different levels of interest of certain countries in PFL; (c) the importance of establishing and keeping contact with departments of Portuguese in some universities in order to expand the teaching and learning of PFL; and (d) the importance of several project management procedures in order to keep contact, as well as the interest of the Portuguese departments in certain universities abroad regarding on-line collaborative projects with Brazil.
\end{abstract}

Keywords: Teletandem; Portuguese as a Foreign Language; on-line synchronous interaction.

\title{
1. Introdução
}

O Projeto Teletandem Brasil: línguas estrangeiras para todos ${ }^{3}$ (Projeto TTB) objetiva colocar alunos universitários brasileiros em contato com alunos universitários estrangeiros para aprenderem, em regime de colaboração e reciprocidade, uma língua estrangeira na qual o outro seja mais competente. Os parceiros, portanto, podem ser nativos ou não nativos, e a colaboração não fica restrita à aprendizagem da língua do parceiro (ou de sua competência), existindo espaços para trocas de informações em múltiplas áreas de conhecimento: culturais, econômicas, políticas, sociais, etc. O teletandem não é um método, mas um contexto virtual, autônomo

3 Projeto temático financiado pela Fundação de Amparo à Pesquisa do Estado de São Paulo (FAPESP). Ver www.teletandembrasil.org. 
e colaborativo no qual os parceiros têm a oportunidade de dialogar com um estudante de outro país a um custo relativamente baixo, pois os pares necessitam de um computador ligado à internet, com banda larga, aplicativo de mensageria instantânea (do tipo Skype, OoVoo e Windows Live Messenger) e uma webcam para ver o parceiro do outro lado. A webcam dá ao teletandem uma característica que o distingue de outras formas de aprendizagem em tandem (BRAMMERTS, 2003), como o tandem face a face e o e-tandem (por telefone, fax, mensagens de texto via celular). Teletandem não é simples bate-papo on-line: eu falo, você me corrige e vice-versa, e nos vemos em uma próxima oportunidade. $\mathrm{O}$ teletandem traz procedimentos sistemáticos para a aprendizagem interativa on-line entre dois parceiros que dizem respeito à frequência dos encontros, à divisão de tempo para cada língua, ao investimento e ao envolvimento de cada um dos parceiros na aprendizagem, a tarefas, à avaliação e, em casos de maior sucesso (como temos experimentado em nosso projeto), à mediação de um professor de línguas estrangeiras. A tarefa deste último é auxiliar os pares a refletirem sobre seus processos de aprendizagem, sobre estratégias e procedimentos, os quais, dependendo do grau de envolvimento dos parceiros, poderão conduzir a uma relativa autonomia na condução do processo de aprendizagem da língua e da(s) cultura(s)-alvo. Ao longo de seus cinco anos de existência, o Projeto TTB apresentou uma relevante produção em nível de publicações (artigos, livros), dissertações e teses e de convênios com departamentos de universidades estrangeiras onde PLE é ensinado. ${ }^{4}$

Neste artigo, apresentamos algumas questões centrais relativas ao gerenciamento de um projeto internacional de aprendizagem de línguas estrangeiras on-line que traz, em uma de suas dimensões, o ensino e a aprendizagem de PLE. Na primeira parte do artigo, traçamos os princípios adotados no projeto quando adaptamos uma ideia não tão nova - a aprendizagem em tandem -, muito utilizada nos anos 1980

4 Ver http://www.teletandembrasil.org/page.asp?Page=25. 
(BRAMMERTS; CALVERT, 2003; WOLFF, 1982), como um contexto on-line de aprendizagem, dando-lhe o nome de teletandem. $\mathrm{Na}$ segunda parte do artigo, apresentamos alguns dados estatísticos relativos aos acessos ao site do projeto sob a forma de desafios institucionais e desafios de abrangência do projeto. Também abordamos aspectos de seu gerenciamento os quais acreditamos ser de importância à comunidade de docentes e pesquisadores que trabalham na área de PLE, enfocando, de modo especial, questões institucionais de parcerias com departamentos de português de universidades estrangeiras, tais como convênios e colaborações entre professores de línguas estrangeiras no Brasil e colegas que ensinam PLE no exterior. Concluímos o artigo com um panorama de futuras pesquisas que emergem do antigo Projeto TTB e enfocam a dimensão cultural das interações on-line em PLE e em uma outra língua estrangeira.

\section{Breve histórico}

Concluído em abril de 2010, após três anos de duração, de colaboração entre equipes de pesquisadores brasileiros e estrangeiros e uma evidente visibilidade nacional e internacional, o projeto temático Teletandem Brasil: línguas estrangeiras para todos ${ }^{5}$ apresentou, por meio de suas dissertações, teses e trabalhos de iniciação científica, ${ }^{6}$ evidências dos potenciais educacionais, colaborativos, pedagógicos e linguísticos da comunicação intercultural on-line por videoconferência entre aprendizes que interagiam virtual e intercontinentalmente na aprendizagem de línguas estrangeiras, por meio da utilização de webcam e dos recursos de aplicativos como Skype, OoVoo e Windows Live Messenger. Além de definir o conceito de teletandem como um contexto virtual, autônomo e colaborativo para a aprendizagem de línguas estrangeiras (ver VASSALLO; TELLES, 2006; TELLES; VASSALLO, 2006; TELLES, 2009; BENEDETTI; CONSOLO; VIEIRA-ABRAHÃO, 2010), o projeto também descreveu

5 (Proc. FAPESP 2006/03204-2).

6 Ver http://www.teletandembrasil.org/page.asp?Page=25. 
as múltiplas maneiras utilizadas pelos aprendizes de tais aplicativos, assim como sugeriu estratégias de implementação do contexto do teletandem em salas de aula (GARCIA, 2010; CAVALARI, 2010, CANDIDO, 2010) e em escolas da rede pública de ensino do Estado de São Paulo (ANDREUFUNO, 2010). Além desses resultados, o Projeto TTB também apontou para os desafios pedagógicos, tecnológicos e procedimentais do trabalho do professor, por meio de sua atuação como mediador na utilização do contexto interativo, autônomo e virtual do teletandem. Por fim, inspirou e colaborou (juntamente com a empresa Talk \& Write ${ }^{7}$ ) com a criação de um novo aplicativo especialmente idealizado para a colaboração on-line, o TAW Soft ${ }^{8}$, que reúne não somente as funções de aplicativos como Skype, mas traz recursos de produção de escrita e de correções colaborativas, além de outros recursos que auxiliam a aprendizagem colaborativa e mais autônoma de línguas estrangeiras.

Entretanto, apesar de seus resultados positivos, o TTB apresentou suas limitações, como todo projeto que se propõe a ser científico. Por um lado, conseguiu dar conta de seus objetivos que focavam: (a) a utilização dos aplicativos de comunicação on-line por videoconferência; (b) as características das interações entre pares que colaboravam on-line na aprendizagem de uma língua estrangeira e o ensino de suas respectivas línguas maternas (ou de proficiência) ${ }^{9}$, e (c) nos procedimentos e nas características do professor de línguas estrangeiras como mediadores e articuladores de um contexto pedagógico, o qual favorece o desenvolvimento da autonomia e da colaboração entre aprendizes de diferentes línguas e culturas. Talvez, por também sermos todos professores e muito ligados à prática pedagógica de sala de aula, nos centramos na descrição e na organização do contexto virtual do teletandem com vistas a possíveis e futuras implementações. Por outro lado, o TTB não se aprofundou nas crescentes evidências surgidas ao longo dos estudos

7 Ver http://www.talkandwrite.com/pt/.

8 Ver http://www.talkandwrite.com/pt/products/tawsoft/.

9 Ver SANTOS, 2008. 
acerca do teletandem como um contexto de aprendizagem de aspectos culturais inerentes à comunicação virtual em teletandem. Embora este não seja o enfoque do projeto (com exceção de alguns estudos, como BENEDETTI; RODRIGUES, 2010; MENDES, 2010), poucos estudos do Projeto TTB evidenciaram a importância e o impacto da dimensão cultural sobre os múltiplos processos subjacentes às interações intercontinentais on-line via teletandem.

\section{Desafios pedagógicos e institucionais}

A iniciativa de implementar um projeto internacional que promova a colaboração on-line entre falantes de português do Brasil e de outras línguas para aprenderem um a língua do outro envolve não somente a simples boa vontade das partes (Brasil e países estrangeiros) de entrar em contato para aprender as línguas e as culturas um do outro. Durante os cinco anos de atividades de pesquisa no âmbito do Projeto TTB, defrontamo-nos com várias dificuldades oriundas, principalmente, da dimensão institucional do projeto no que tange ao contato com os departamentos e os professores de universidades estrangeiras. Houve necessidade de visitas às instituições, palestras, explicações sobre o projeto e demonstrações de sessões de teletandem feitas entre os laboratórios da UNESP e os laboratórios dessas instituições, os quais, frequentemente, não estavam equipados com webcams para realizarmos a proposta de comunicação via teletandem.

Além disso, nos defrontamos com as diversas culturas de se ensinar línguas estrangeiras e os objetivos que o ensino de PLE tinha em cada uma delas. Muitas vezes, o ensino de PLE nessas instituições focava a literatura, questões culturais, econômicas e sociais a respeito do Brasil, e os professores não compreendiam que tais enfoques poderiam ser dados às interações online via teletandem para promover a aprendizagem de ambas as línguas.

Começamos por adotar o sistema de inscrições on-line no site do Projeto TTB. Todos os interessados deveriam se inscrever para obter os 
respectivos parceiros. Os pares eram, então, colocados juntos seguindo os critérios de disponibilidade de horário e de matrícula regular no curso de Letras da UNESP e em algum curso da universidade estrangeira. A dificuldade dos alunos em estabelecer o contato inicial, após terem recebido os e-mails do projeto, revelando o nome e o endereço do parceiro, era difícil e as negociações exigidas, ao longo do processo não direcionavam os alunos aos seus objetivos de iniciarem suas sessões de teletandem. O caminho para a autonomia precisava ser facilitado por um professor-mediador. $\mathrm{O}$ estudo de Garcia (2010) apresenta detalhados e interessantes relatos acerca das negociações iniciais e durante os processos de teletandem, inclusive apresentando as trocas iniciais de e-mail entre os alunos, tentando planejar o encontro, os dias e os horários.

O acompanhamento das parcerias, no entanto, ficava difícil. Para saber se uma parceria tinha dado certo (se os encontros permaneciam regulares por um período de, pelo menos, oito semanas, com um encontro semanal de duas horas), tínhamos que acessar os alunos e/ou professores das disciplinas. Dada a característica autônoma do teletandem, deixamos de prever e idealizar formas de avaliação e seguimento das sessões (ver CAVALARI,2010 para questões de avaliação no teletandem). Vários estudos sobre mediação realizados no Brasil, no Programa de Pós-Graduação em Estudos Linguísticos da Unesp São José do Rio Preto, puderam manter um razoável contato com as duplas (KANEOYA, 2008; ROCHA, 2009; VASSALLO, 2010). Porém as duplas encontravam muitas dificuldades em manter a constância dos encontros. Além disso, tanto no Brasil quanto nas instituições estrangeiras parceiras o status da atividade de teletandem era o de uma atividade extra - um apêndice ao curso principal de português ou da língua estrangeira, muitas vezes não avaliado.

\section{Desafios de abrangência e acessibilidade}

Mas qual seria a abrangência de todo esse aparato institucional e pedagógico, arquitetado no âmbito de um projeto temático que pretende 
colocar os brasileiros, a cultura brasileira e a língua portuguesa em contato com outros povos com o intuito de oferecer um contexto virtual e colaborativo para compartilhamento de experiências, língua e cultura dos povos envolvidos?

A parte administrativa do site do Projeto (acesso restrito somente aos administradores) traz alguns dados relevantes a todos aqueles interessados em divulgar e ampliar o ensino e a aprendizagem de PLE. Dizem respeito a cerca de 950 parcerias efetuadas pelo site no transcorrer de quase seis anos de atividades (de junho de 2006 a março de 2011). A maioria dessas parcerias foram realizadas com instituições universitárias estrangeiras, com as quais mantemos convênios ou contatos mais constantes, ou seja, aquelas instituições que se mantiveram nos enviando alunos ao longo de todos os anos. Os países envolvidos são aqueles das línguas adotadas no TTB: alemão, espanhol, francês, italiano e inglês. Entretanto, pelo fato de não adotarmos uma política de falantes nativos, não pudemos manter o controle de qual país enviou o maior número de participantes para determinada língua. Por exemplo, um aluno de uma universidade da Tunísia poderia pedir um parceiro brasileiro para um teletandem francês $\mathrm{x}$ português; ou mesmo como aconteceu com a Suécia, que, dada a carência de alunos que falavam inglês e a grande demanda de alunos que desejavam aprender esta língua aqui no Brasil, nos enviou alunos suecos para realizarem teletandem em inglês x português ou francês x português, não sendo nem o inglês nem o francês línguas nativas dos suecos.

A Figura 1 ilustra a abrangência do site do Projeto TTB durante o período medido entre 9 de março de 2007 e 9 de março de 2011. É necessário, contudo, olhar para esses dados com certo cuidado. É possível que nem todos os internautas possam ter acessado o site do Projeto TTB com o intuito de aprender PLE, mas com múltiplos outros objetivos. No entanto, isso não desfaz a ideia de que o site nos valeu como um importante instrumento, não somente para a divulgação do projeto, mas para a projeção das possibilidades de se conseguir um parceiro para a prática de PLE. No período de quatro anos, acessaram o site 68.918 pessoas provenientes de 132 países. 


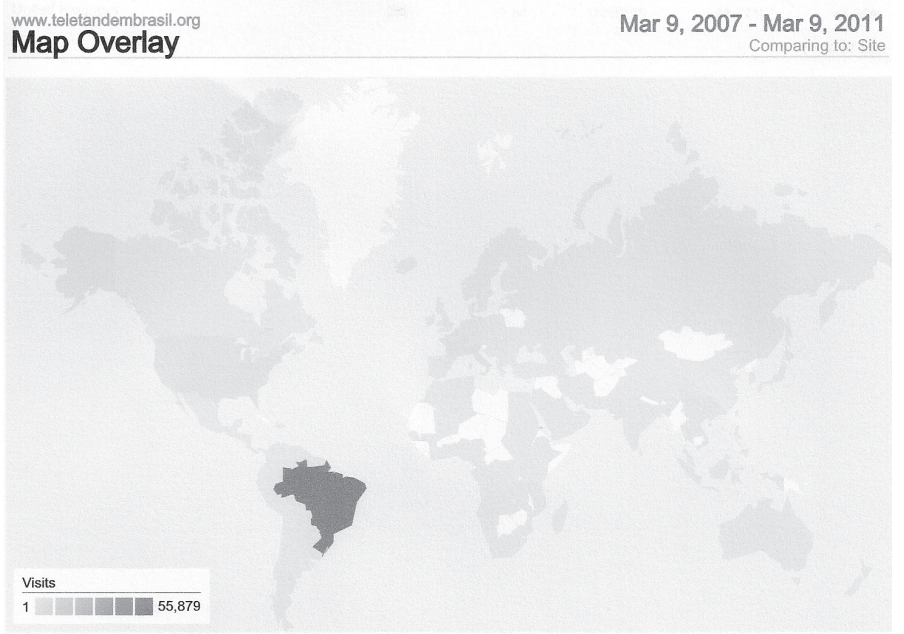

68,918 visits came from 132 countries/territories

Figura 1: Abrangência do site do Teletandem Brasil no mundo

Pensamos também sobre os países que mais acessaram o site, e muitos foram aqueles com os quais mantivemos contato (convênios). A Figura 2 ilustra a classificação dos dez primeiros países no que tange à quantidade de acessos ao site.

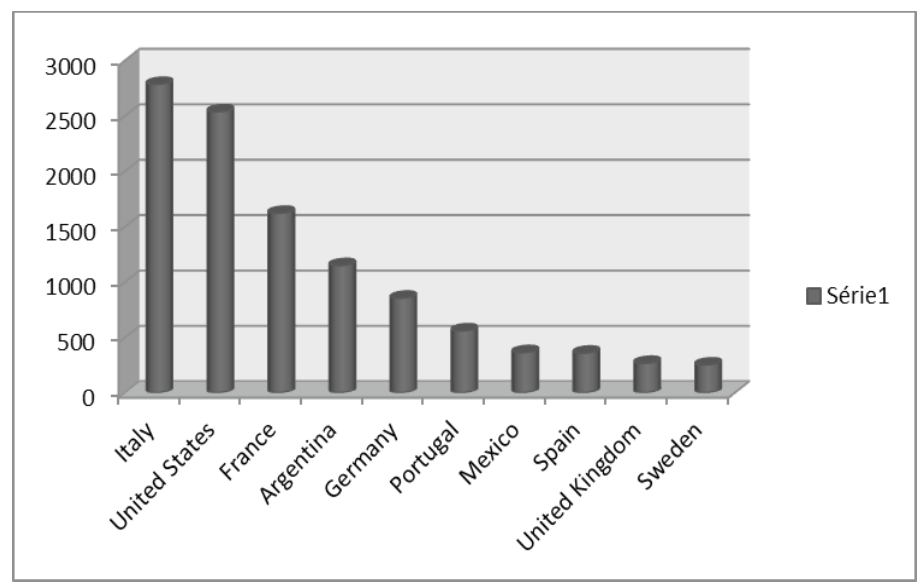

Figura 2: Dez países que mais acessaram o site (período: 09/03/2007-09/03/2011) 
De acordo com os dados colhidos pelo Google Analytics, os dez países que mais acessaram o site foram: Itália; Estados Unidos; França; Argentina; Alemanha; Portugal; México; Espanha; Reino Unido e Suécia. Há alguns aspectos curiosos desta classificação. Em primeiro lugar, seria importante considerar o tamanho dos demais países em relação aos Estados Unidos. O fato de estar em segundo lugar não significa que os EUA estejam mais interessados na língua portuguesa ou no Brasil. Em segundo lugar, a posição da Alemanha revela um alto interesse no site, no Brasil ou no português, dado ao seu tamanho em comparação com países de grande extensão territorial e grande população, como Estados Unidos e México. Em terceiro lugar, as posições da Argentina, do México e da Espanha, dentre os 10 países que mais acessaram, revela o interesse dos países hispânicos no português, possivelmente por vários motivos, que já conhecemos: a intercompreensão e a proximidade das línguas e das culturas e, no caso argentino, o Mercosul. A posição da Suécia deve-se aos contatos realizados com a Universidade de Estocolmo, por meio de um colega extremamente colaborativo. Provavelmente Portugal tem um número alto de acessos devido ao interesse dos portugueses em aprender línguas estrangeiras. $\mathrm{O}$ caso mais curioso nesses dados, entretanto é a posição do Reino Unido - nono lugar. Este país não tem participantes ou instituições no Projeto TTB. Várias tentativas de contato com departamentos de PLE do Reino Unido não surtiram efeito, e até o momento não temos dados de que alguma universidade ou cidadão daquele país faça teletandem com algum de nossos alunos.

O Brasil tem um número altíssimo de acessos para o mesmo período (55.879), advindos, principalmente, da Região Sudeste, podendo indicar um alto interesse dos brasileiros desta região na proposta do Projeto TTB (ver Figura 3), ou pelo simples fato de ter uma maior densidade populacional (como é o caso dos Estados Unidos, na Figura 2), com amplo acesso à internet. 


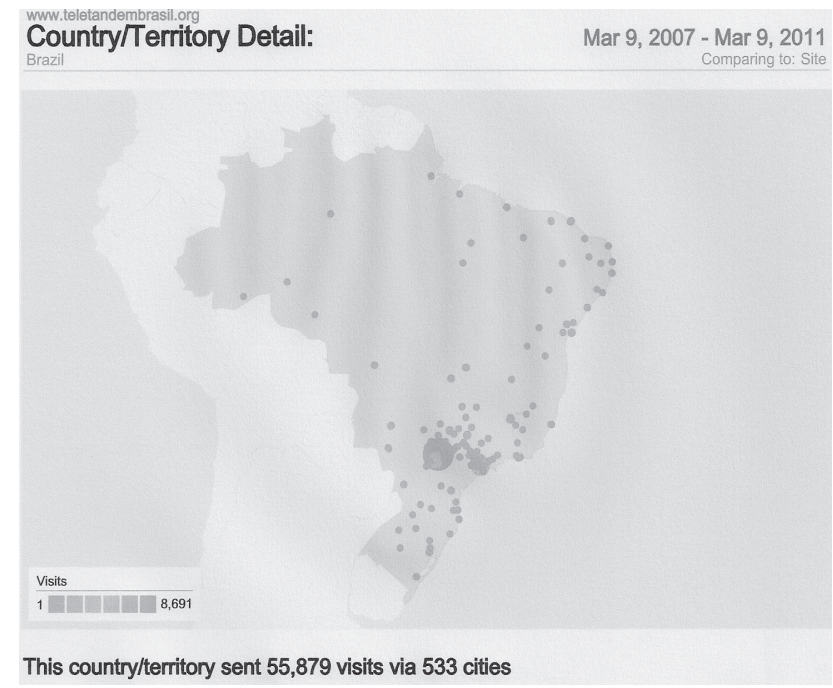

Figura 3: Regiões e cidades brasileiras que mais acessaram o site (período: 09/03/2007-09/03/2011)

Retornando aos três países que mais acessaram o site (Itália, Estados Unidos e França), é curioso verificar as cidades ou regiões de onde os acessos vieram. Eles podem indicar as instituições ou cidades que têm maior interesse em PLE, ou no Brasil e sua cultura. A Figura 4 mostra as cidades italianas que mais acessaram o site no período considerado.

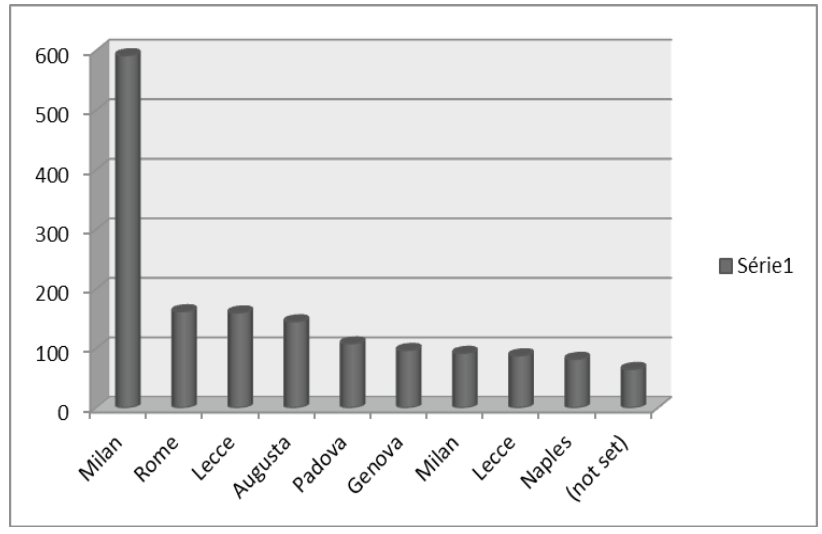

Figura 4: Regiões da Itália que mais acessaram o site (período: 09/03/2007-09/03/2011) 
Excluindo-se Milão, por sua alta densidade populacional, e as cidades não captadas pelo Google Analytics (not set, no gráfico), ficamos com oito cidades, das quais Lecce e Milão se repetem por mais uma vez (o Google Analytics registra como Lecce e Milão as pequenas cidades vizinhas a elas e por isso se repetem). Temos então Roma, Lecce, Augusta, Pádua, Gênova e Nápoles com maior número de acessos durante o período considerado. $\mathrm{O}$ alto número de acessos por Roma, Lecce e Nápoles se deve ao fato de termos universidades conveniadas nessas cidades que nos enviaram o maior número de estudantes (principalmente Lecce e Nápoles ${ }^{10}$ ) para a prática de teletandem. Os alunos, no caso dessas três universidades, podem ter acessado o site para melhor conhecerem o projeto e a Unesp. Podemos inferir também, pelo número de acessos, que Augusta, Pádua e Gênova são cidades com potencial de interesse no projeto, no Brasil e/ou em PLE. As universidades dessas cidades, no entanto, não nos enviaram alunos para a prática de teletandem, exceto Pádua, que nos enviou cerca de 10 alunos.

O segundo país que mais acessou o site do TTB no período de 9 de março de 2007 a 9 de março de 2011 foram os Estados Unidos. A Figura 5 ilustra a classificação dos estados americanos por número de acessos ao site do projeto. Os dados oferecidos pelo Google Analytics no que diz respeito aos Estados Unidos são muito mais precisos e corroboram com o número de universidades americanas participantes do projeto. Dos dez estados americanos que mais acessaram o site, somente três não têm universidades que participam do projeto (Nova York, California e Kentucky). O estado de Maryland, mesmo não tendo universidades que participam do TTB, aparece computado pelo Google Analytics, porque está muito próximo ao Distrito de Columbia, onde a Georgetown University, participante do projeto, está localizada. É provável, portanto, que muitos alunos de Georgetown que residem nos estados de Maryland ou Virgínia tenham acessado o site para melhor conhecer o projeto e obter informações sobre como proceder durante as sessões de teletandem. É importante frisar o fato

10 Na verdade, foi a cidade de Salerno que mais acessou o site. Como no caso de Lecce e Milão, o Google Analytics registra as pequenas cidades ou vilas como a cidade maior mais próxima. 
de que poucas são as universidades localizadas nos outros sete estados que mais acessaram o site. Em cada um deles há somente uma universidade que participa do projeto, e não mais.

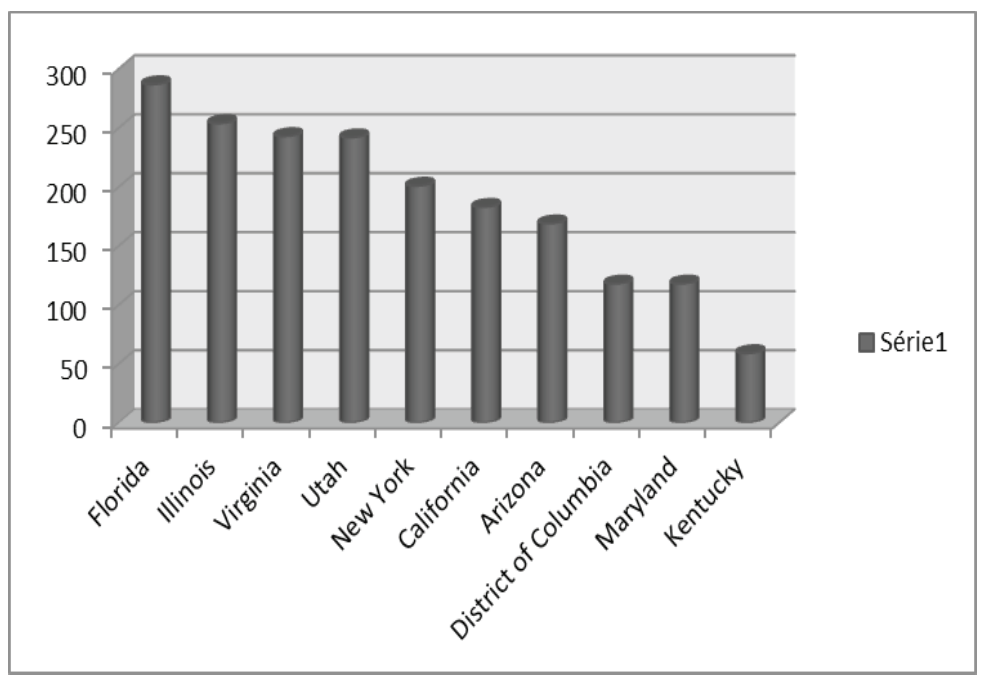

Figura 5: Estados dos Estados Unidos que mais acessaram o site (período: 09/03/2007-09/03/2011)

Podemos inferir que existem possíveis interesses dos estados de Nova York, Califórnia e Kentucky, mesmo sem afiliações ao Projeto TTB. No caso da Califórnia, como no da Flórida, a presença de uma grande comunidade latina, formada por brasileiros e hispânicos, tenha sido a causa do alto número de acessos. Nova York se justifica pela grande densidade populacional do estado, principalmente na cidade de Nova York, onde há uma grande comunidade de filhos de brasileiros e americanos interessados no Brasil. Entretanto, somente no mês que este trabalho estava sendo escrito é que a Columbia University iniciou uma parceria com o Laboratório de Teletandem da UNESP São José do Rio Preto, juntamente com a Universidade de John Hopkins e Universidade da Geórgia (esta última não aparece nas estatísticas levantadas pelo Google Analytics). Os estados da Flórida, Nova York e Califórnia, no entanto, permanecem como locais de grande potencial para implementação de programas on-line de PLE. 
A questão, no entanto, é firmar os convênios de colaboração acadêmica com as instituições universitárias desses três estados, algo que se mostrou muito difícil durante os cinco anos de existência do Projeto TTB. As razões que nos parecem mais patentes para tal dificuldade são a visão, a estrutura e os objetivos pedagógicos dos departamentos de Português (ou de Espanhol/ Português - frequentemente estão atrelados) dessas instituições. Para eles, a comunicação e a colaboração em teletandem são vistas como atividades extracurriculares, atividade de bate-papo, e não como algo orgânico que faça parte do currículo e do programa de ensino de PLE.

Os dados relativos à França, o terceiro país que mais acessou o site, não trouxeram informações além daquelas sobre as quais que já tínhamos conhecimento. Somente duas universidades francesas participam do Projeto TTB trazendo alunos franceses para colaborarem em teletandem com alunos brasileiros - referimo-nos às universidades Charles-de-Gaulle (Lille III) e Lumière (Lyon II). Ambas, com variações na frequência, nos enviaram alunos franceses durante esses cinco anos, tendo Lyon iniciado sua colaboração um pouco mais tarde, após o início do projeto, em 2007. Os resultados são curiosos - como é possível a França ocupar o terceiro lugar em acessos ao site se somente duas universidades se interessaram em nos enviar alunos para a prática de teletandem? Uma possível resposta é a intensidade com a qual ambas as universidades acessam o site, mas com um baixo número de alunos franceses participando do projeto. Verificando a Figura 6, notamos as cidades que tiveram maior acesso ao site: 


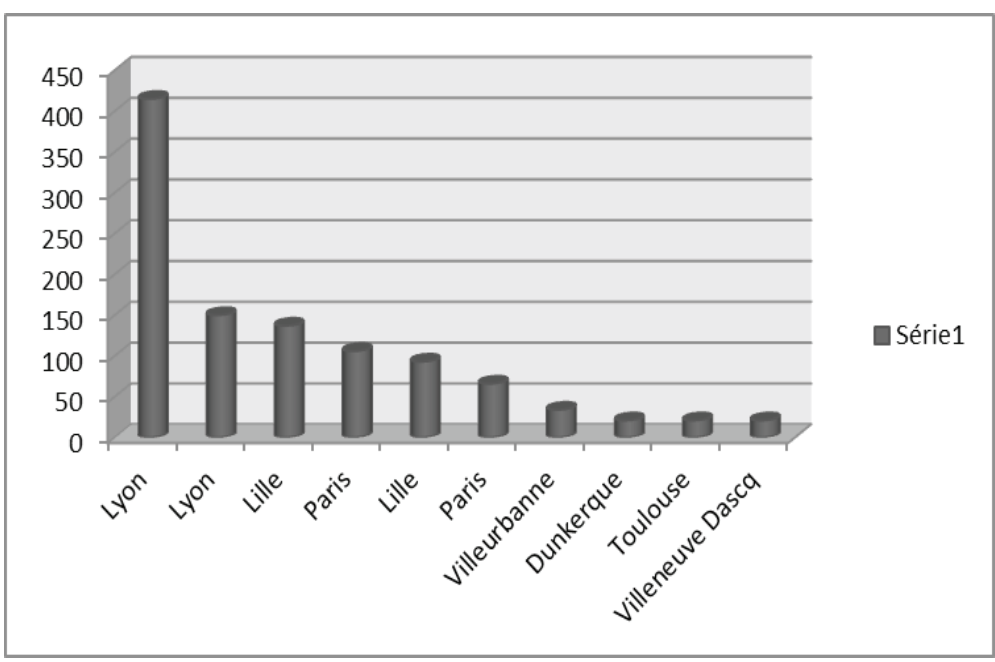

Figura 6: Cidades da França que mais acessaram o site (período: 09/03/2007-09/03/2011)

Os dados para a França podem ser interpretados facilmente e podem ser divididos em três grupos de cidades francesas: Lyon, Lille, Paris e Toulouse. Lyon e Lille (as cidades com cujas universidades mantemos convênio) e se repetem por duas vezes, dada a quantidade de pequenas cidades vizinhas onde residem seus alunos (Villeurbanne, ao lado de Lyon, e Dunkerque e Villeneuve D'Ascq, vizinhas a Lille). O grande número de acessos de Paris ocorre também devido à sua densidade demográfica, o mesmo acontecendo com Toulouse provavelmente. Em suma, o potencial para o desenvolvimento de PLE na França, segundo mostram esses dados, está em Lille e em Lyon, seguido de Paris e Toulouse, essas duas últimas devido à densidade populacional.

Finalmente, no que tange à visibilidade e à abrangência do projeto, é importante informar que a maior parte dos acessos ao nosso site foi feita pelos modos do tráfico direto (36.29\% - quando a pessoa digita o endereço do site) e pelo modo de busca no motor de pesquisa (36.23\% - quando a pessoa digita uma palavra-chave). As palavras-chave mais digitadas para encontrar nosso site na internet foram teletandem, teletandem Brasil, projeto de pesquisa, o endereço do site - www.teletandembrasil.org - e, 
curiosamente, www.gramaticaon-line.com. Os acessos por referência de outros sites (27.44\%) aparecem em menor número. A Figura 7 ilustra essas estatísticas:

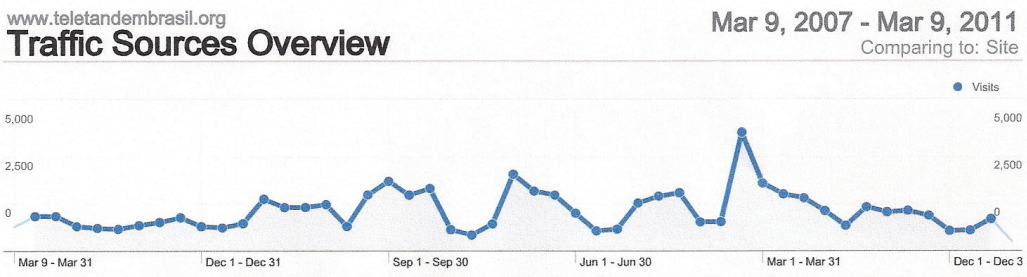

All traffic sources sent a total of 68,918 visits
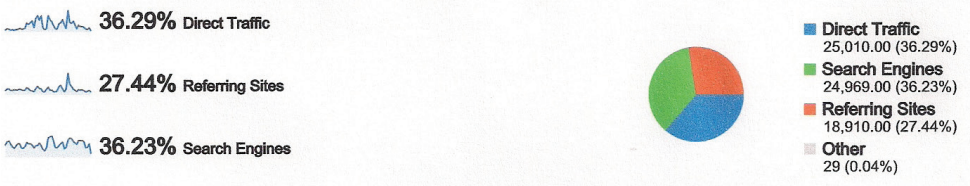

Figura 7: Fontes de tráfego de acesso ao site (período: 09/03/2007-09/03/2011)

A existência de um site para visibilidade e abrangência de um programa de PLE a distância nos parece, portanto, muito importante. A Figura 1 nos mostra a grande abrangência do projeto pelo número de acessos provenientes de 132 países, de todos os continentes, após cinco anos de atividades.

Para concluir esta parte do trabalho, referente à abrangência e à visibilidade do projeto, mas que também nos leva a algumas conclusões sobre a projeção do ensino/aprendizagem de PLE no mundo, é importante frisar a importância dos aspectos geográficos e, como consequência, o aspecto sazonal para a intensidade ou para a frequência das atividades online de teletandem com as universidades estrangeiras.

Em primeiro lugar, como brasileiros, estamos localizados no hemisfério sul. Para a comunicação on-line com países também localizados neste hemisfério não há problema, a não ser com questões de pequenos fusos horários. Isso faz com que programas de comunicação síncrona on-line com países latino-americanos vizinhos ao Brasil e abaixo da linha do Equador 
apresentem somente o problema de diferença de horário. Observamos que programas com Argentina e Uruguai podem ser facilmente implementados, uma vez resolvidos os problemas técnicos de banda larga, ainda apresentados por esses dois países de fala espanhola.

Em segundo lugar, a localização do Brasil no hemisfério sul e da maioria dos países com os quais mantemos interesses linguísticos que estão localizados no hemisfério norte nos impõe a limitação do período letivo das universidades. No hemisfério norte, o primeiro semestre letivo inicia-se ao redor de setembro e vai até dezembro (próximo ao Natal), enquanto no hemisfério sul estaremos no segundo semestre (agosto a dezembro). O caso do segundo semestre apresenta ainda mais problemas: no hemisfério norte inicia-se em janeiro e termina em meados de maio, aproximadamente. Enquanto alunos no hemisfério norte estão estudando, nos meses de janeiro e fevereiro, estamos em férias de verão. Restam-nos, portanto, somente março, abril e metade de maio para realizar algum tipo de colaboração online, servindo os primeiros 15 dias de março para "acertarmos o passo" no novo ano letivo.

As diferenças de fuso horário e de início/fim de anos letivos apresentamse, assim, como sérias dificuldades para a implementação de um programa on-line colaborativo de PLE + língua estrangeira. Os meses de intenso trabalho ficam, portanto, restritos aos períodos de 60 dias (meados de março a meados de maio) e 105 dias (setembro à primeira semana de dezembro), isso sem contar com o fato de que algumas universidades europeias iniciam seu ano letivo em meados de outubro.

Durante os cinco anos do Projeto TTB, o acesso ao site também revela a periodicidade das relações em teletandem. A Figura 8 ilustra os períodos em que o projeto esteve mais ativo, com vários alunos estrangeiros requisitando pares. Notem-se os picos nos números de acesso relativos aos períodos de intenso trabalho no hemisfério norte ou preparando-se para a entrada do ano letivo naquele hemisfério. 


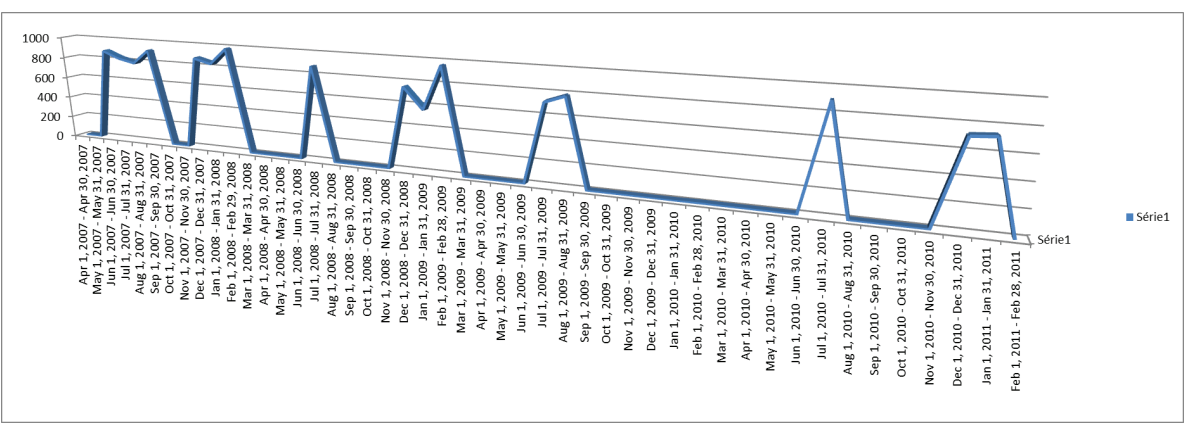

Figura 8: Períodos de atividade do projeto

(período: 09/03/2007-09/03/2011)

\subsection{Desafios pedagógicos}

Por fim, os desafios antes descritos trazem um impacto sobre a pedagogia de PLE e ensino/aprendizagem de LE. Esses aspectos desafiadores estão interligados, e todos conspiram para os resultados qualitativos e quantitativos dos projetos interinstitucionais de colaboração on-line de ensino/aprendizagem síncronos de línguas estrangeiras. Existem aspectos institucionais e pedagógicos nesse tipo de colaboração que acreditamos serem importantes considerar: (a) o status do PLE na instituição e no currículo; (b) o status do teletandem como um novo contexto virtual e colaborativo para a aprendizagem síncrona de LE no currículo das universidades estrangeiras; (c) as diferentes representações do que sejam ensinar e aprender uma língua estrangeira; e (d) a complexa e desafiadora dimensão cultural dessas interações on-line síncronas.

O status do português no currículo da universidade estrangeira é um fator importante para o sucesso de um projeto como o TTB. Em muitas universidades estrangeiras, o português compete com o espanhol, com o francês e com o alemão, tendo havido nos últimos anos uma explosão no número de alunos de chinês e árabe. O relatório da Associação de Departamentos de Línguas Estrangeiras (o ADFL Bulletin 2006) indica que a matrícula em línguas estrangeiras subiu 12,9\% de 2002 a 2006, enquanto em português o aumento foi de $22,4 \%$ no mesmo período e de 
21\% nos anos de 1998-2002. ${ }^{11}$ Parece que a opção por estudar português resulta do papel que o Brasil vem desempenhando nas relações bilaterais e comerciais com outros países. Para um projeto de telecolaboração on-line síncrona, isso é importante em razão do número de alunos estrangeiros que estudam português e se interessam em fazer sessões de teletandem.

Em segundo lugar, durante o projeto, o papel do teletandem no currículo das universidades estrangeiras com as quais tivemos contato foi o de um apêndice ou de uma atividade extra às aulas frontais tradicionais levadas a cabo nas instituições. Ao contatar os departamentos de português no exterior para propor o teletandem como atividade para seus alunos, a resposta dos professores era frequentemente lacônica, desconfiada e com várias dúvidas sobre como proceder. Além disso, por se tratar de um projeto que incluía não somente o ensino/aprendizagem, mas também a pesquisa, os professores desistiam premidos pelas rígidas regras de ética de pesquisa dessas instituições. Como em grande parte das instituições educacionais, a pesquisa ocupa uma posição distante do ensino e da aprendizagem sobre os quais temos tanto que saber e questionar todo o tempo. Ao longo de 2010, com a parceria corajosa de certos colegas professores de PLE no exterior, conseguimos implementar o teletandem na sala de aula, como parte das aulas: os grupos de alunos reúnem-se nos laboratórios dos respectivos países e iniciam as interações em português e na língua estrangeira supervisionados pelos professores presentes na sala, que acompanham o processo de aprendizagem em teletandem durante e após as sessões (verificando os trabalhos realizados).Dessa forma, aos poucos fomos abandonando nossa ideia de simplesmente formar as parcerias e esperar que elas se organizassem de modo autônomo (aliás, um dos pilares da aprendizagem em tandem). Concluímos que a autonomia necessita ser aprendida e que, frequentemente, os sistemas educacionais e a escola não promovem contextos para que os alunos se comportem de

11 Ver o volume especial da Portuguese Language Journal sobre programas de português nos Estados Unidos: Milleret, Margo, Ed. "Building, Growing, and Maintaining Portuguese Programs". Portuguese Language Journal 4 (Fall 2010): http://www.latam.ufl.edu/PLJ/articles.html. Acesso em: 08 ago 2011. 
modo autônomo. Mesmo assim, ainda temos um alto grau de autonomia dos alunos durante as sessões de teletandem. Nosso papel, hoje em dia, é promover a organização dos encontros on-line, algo que se provou extremamente difícil para os alunos durante os primeiros três anos de projeto (ver GARCIA, 2010, para uma detalhada descrição acerca das negociações entre os pares, após terem recebido a notícia, por e-mail, de que eram parceiros).

Em terceiro lugar, as diferentes representações do que seja ensinar e aprender uma língua estrangeira são também importantes no que tange ao sucesso das parcerias de teletandem. Os alunos que participaram de nosso projeto chegaram a apresentar tensões com seus parceiros em função dos diferentes níveis de comprometimento com a aprendizagem e também pelas estratégias que utilizaram para aprender as línguas. As diferentes culturas trazem diferentes representações desses processos, e não somente deles, mas também das variantes linguísticas das línguas estrangeiras com que entram em contato. $\mathrm{O}$ contexto virtual do teletandem, como qualquer outro contexto interacional, é lugar de instauração de disputas por identidades e por poder. A própria decisão sobre o que falar e o que prover como informação durante uma sessão de teletandem é uma relação de poder (VASSALLO, 2010).

Por fim, todos os três desafios anteriormente descritos convergem para a complexa e desafiadora dimensão cultural dessas interações on-line síncronas que deve ser levada em conta em um programa on-line de PLE (NAKAYAMA; HALUALANI, 2010). Identidade e diferença caminham lado a lado (SILVA, HALL e WOODWARD, 2000; SILVA, 2007), em um processo colaborativo e (na medida do possível) autônomo de teletandem. Ambas serão estudadas, em continuidade ao Projeto TTB. A interação em teletandem é lugar de afirmações de identidade e constantes representações das diferenças, sendo que uma das principais, a que traz sentido aos encontros, é a representação dos alunos do ensinar e aprender uma língua estrangeira. 


\section{Considerações finais}

Neste artigo, apresentamos os objetivos de um projeto de comunicação linguística e intercultural on-line no qual questões importantes relativas ao ensino e aprendizagem de PLE estão interligadas. Acreditamos na importância dos projetos on-line de PLE para a divulgação, a baixo custo, da língua e das culturas existentes no Brasil. O Ministério das Relações Exteriores do governo do Brasil e sua Divisão de Promoção da Língua Portuguesa (DPLP ${ }^{12}$ ) deveriam estar atentos ao potencial de projetos deste tipo, pois eles podem expandir o interesse no português do Brasil e, ao mesmo tempo, abrir espaços para que os brasileiros possam refletir acerca de sua língua e sua cultura pelo contato com colegas estrangeiros que trazem suas próprias visões acerca no Brasil e da língua portuguesa.

As evidências das quais não pudemos dar conta no Projeto TTB nos encorajaram a dar continuidade aos estudos com um novo projeto temático, que agora enfocará a dimensão cultural das interações virtuais em teletandem e cujo título é Teletandem: transculturalidade na comunicação on-line em linguas estrangeiras por webcam. Por certo, tais evidências transcendem o próprio contexto do teletandem e é importante que sejam pesquisadas por estarem presentes em qualquer interação (presencial ou virtual) no mundo globalizado de hoje, em que as tecnologias transcendem fronteiras e proveem as oportunidades de contato a um mínimo custo financeiro. $\mathrm{O}$ contexto de teletandem traz em seu bojo uma tecnologia que a cada dia se torna mais acessível a todos e que já faz (ou, logo fará) parte da rotina das pessoas, conforme os equipamentos e conexões com a internet se tornam mais acessíveis ao público.

Sendo assim, uma consequência para a aprendizagem e para o ensino de PLE já pode ser levantada: ficou mais fácil entrar em contato com o

12 Várias tentativas de contato com a Divisão de Promoção da Língua Portuguesa (DPLP) do Ministério das Relações Exteriores do governo do Brasil foram realizadas durante o projeto, mas não obtivemos resposta ou qualquer manifestação de interesse na implementação de tais projetos. A rubrica e o apoio do MRE e da DPLP certamente teriam garantido a participação de várias outras instituições universitárias estrangeiras no projeto, promovendo, assim, o contato de cidadãos brasileiros com o exterior, além de divulgar a língua portuguesa falada no Brasil a um baixo custo. 
Brasil. Se para muitos estrangeiros se tratava de um país distante e caro para se alcançar, agora, os brasileiros, a língua portuguesa e as culturas do Brasil podem ser acessados por meio da comunicação on-line, inclusive com imagens de webcam proporcionadas pelos aplicativos. Ao mesmo tempo, os brasileiros têm a oportunidade não só de projetar suas identidades e diferenças, como também entrar em contato com as de seus parceiros. A repercussão educacional desses contatos, se bem explorados por professores bem preparados de PLE e outras línguas estrangeiras, já pode ser notada no âmbito do Projeto TTB e das instituições estrangeiras nossas parceiras (ELSTERMANN, 2008; SALOMÃO, 2008; MOITEIRO, 2009; LEONE, 2009; BENEDETTI, 2010).

Sob a forma de um novo projeto, partimos agora para investigar a relação aprendizado de línguas estrangeiras e aprendizado de cultura na comunicação intercultural on-line, via aplicativos de videoconferência, entre pessoas de diferentes culturas. $\mathrm{O}$ objetivo da equipe de pesquisadores é investigar a tese de que a comunicação intercultural e intercontinental por meio de aplicativos de videoconferência on-line, via teletandem, oferece oportunidades, a baixo custo, para que o aluno brasileiro desenvolva sua cidadania transcultural, mesmo habitando em um país de dimensões geográficas continentais, como o Brasil, e sendo circunscrito em um isolamento do mundo, imposto pela própria geografia e pelas condições econômicas que o impedem de realizar viagens para os países da línguaalvo. As múltiplas possibilidades de um projeto deste tipo para a formação inicial e continuada de professores de línguas estrangeiras em nossos cursos de Letras (em particular o potencial para a prática e melhoria da proficiência oral) já foram também detectadas (TELLES, 2009; BENEDETTI; CONSOLO; ABRAHÃO, 2010).

Os dados a serem produzidos neste futuro projeto nos darão evidências empíricas, analisáveis em termos de língua utilizada e conteúdo veiculado das interações on-line, para verificarmos o papel dessas interações como contextos propícios para a construção da competência e da cidadania intercultural dos alunos brasileiros e estrangeiros. Nossa intenção é verificar 
a proposta de Byram (2010) que defende uma visão mais radical da educação de línguas, na qual métodos de conteúdo e aprendizagem linguisticamente integrados (language integrated learning - CLIL) indicam um avanço, se condições forem oferecidas pelo contexto de aprendizagem que enfocam tanto o conteúdo quanto a forma da língua-alvo (caso, do contexto do teletandem). Para Byram (2010) "este conteúdo em questão deveria se apoiar na educação para a cidadania, enriquecendo-a por meio da atenção para a competência comunicativa intercultural, dando conteúdo substancial e significativo às aulas de língua [algo também já evidenciado nas pesquisas sobre teletandem]" (p. 320). Para o autor, a aquisição de competências da cidadania intercultural seriam as metas e objetivos a serem atingidos, realizando objetivos educacionais e instrumentais/funcionais.

\section{Referências}

ALRED, Geof; BYRAM, Michael. Becoming an intercultural mediator: a longitudinal study of residence abroad. Journal of Multilingual and Intercultural Development, v. 23, n. 5, p. 339-352, 2002.

ANDREU-FUNO, Ludmila B. Teletandem e formação continua de professores vinculados à rede pública de ensino do interior paulista: um estudo de caso. 2010. 195 f. Dissertação (Mestrado em Estudos Linguísticos). UNESP/ IBILCE, São José do Rio Preto, 2010.

BENEDETTI,Ana Mariza; RODRIGUES,Denize Gisele.Choques linguísticoculturais e o desenvolvimento da competência intercultural em teletandem. In: BENEDETTI, Ana Mariza; CONSOLO, Douglas A.; VIEIRA-ABRAHÃO, Maria Helena. Pesquisas em ensino e aprendizagem no Teletandem Brasil: linguas estrangeiras para todos. Campinas: Pontes, 2010. p. 89-104.

BENEDETTI, Ana Mariza. Aplicaciones potenciales del contexto teletandem para el aprendizaje de lenguas extranjeras. Moderna Sprak, v. 104, n. 1, p. 42-58, 2010. Disponível em: <http://ojs.ub.gu.se/ojs/index. php/modernasprak>. Acesso em: 08 ago 2011. 
BENEDETTI, Ana Mariza; CONSOLO, Douglas A.; VIEIRAABRAHÃO, Maria Helena. Pesquisas em ensino e aprendizagem no Teletandem Brasil: linguas estrangeiras para todos. Campinas: Pontes, 2010.

BRAMMERTS, Helmut; CALVERT, Mike. Learning by communicating in tandem. In: LEWIS, Tim; WALKER, Leslie. Autonomous language learning in tandem. Sheffield, UK: Academy Electronic Publications, 2003. p. 45-59.

BRAMMERTS, Helmut. Autonomous language learning in tandem. In: LEWIS, Tim; WALKER, Leslie. Autonomous language learning in tandem. Sheffield, UK: Academy Electronic Publications, 2003. p. 27-36.

BYRAM, Michael. Linguistic and cultural education for Bildung and citizenship. The Modern Language Journal, v. 94, n. 2, p. 317-321, 2010.

CANDIDO, Juliana. Teletandem: sessões de orientação e suas perspectivas para o curso de Letras. 2010. Dissertação (Mestrado em Estudos Linguísticos) - UNESP/IBILCE, São José do Rio Preto, 2010.

CAVALARI, Suzi M. S. A autoavaliação em um contexto de ensinoaprendizagem de linguas em tandem via chat. 2010. Tese (Doutorado em Estudos Linguísticos) - UNESP/IBILCE, São José do Rio Preto, 2010.

ELSTERMANN, Anna Katharina. Vom Präsenztandem der 1960er Jahre zum internetgestutzten Teletandem des FASK Mainz in Germersheim und der UNESP/Assis, Brasilien. 2008. Dissertação (Mestrado em Estudos Linguísticos) - Johannes Gutemberg Universität, Meinz, 2008.

GARCIA, Daniela N. M. Teletandem: acordos e negociações entre os pares. 2010. Tese (Doutorado em Estudos Linguísticos) - UNESP/IBILCE, São José do Rio Preto, 2010.

GIMENEZ, Telma. Beyond communication: teaching English in the age of globalization. Claritas, v. 13, p. 22-30, 2007.

KANEOYA, Marta Lúcia C. K. A formação inicial de professoras de línguas paralem contexto mediado pelo computador (teletandem): um diálogo entre 
crenças, discurso e reflexão profissional. 2008. Tese (Doutorado em Estudos Linguísticos) - UNESP, São José do Rio Preto, 2008.

LEONE, Paola. Comunicazione mediata dal computer e apprendimento linguistico: gli incontri teletandem. Studi di Glottodidattica, v. 3, n. 1, p. 1-20, 2009. Disponível em: <http://ojs.cimedoc.uniba.it/index.php/ glottodidattica/article/view/77>. Acesso em: 08 ago. 2011.

MARTINS MOITEIRO, Nicole. Action research on teletandem: an analysis of virtual intercultural communication between students from Brazil and Germany. Diplomarbeit. 2009. Dissertação (Mestrado em Estudos Linguísticos) - Johannes Gutemberg Universität, Meinz, 2009.

MENDES, Ciro M. Antiamericanismo e outras crenças relacionadas ao processo de ensino-aprendizagem de língua inglesa: um estudo sobre a modalidade teletandem como provedora de contato intercultural. In: BENEDETTI, Ana Mariza; CONSOLO, Douglas A.; VIEIRAABRAHÃO, Maria Helena. Pesquisas em ensino e aprendizagem no teletandem Brasil: linguas estrangeiras para todos. Campinas: Pontes, 2010. p. 105-121.

MILLERET, Margo (Org.). Portuguese Language Journal, v. 4, volume temático Building, growing, and maintaining portuguese programs, Fall 2010. Disponível em: <http://www.latam.ufl.edu/PLJ/articles.html>. Acesso em: 08 ago 2011.

NAKAYAMA, Thomas K.: HALUALANI, Rona T.. The handbook of critical intercultural communication. West Sussex, UK: Blackwell Publishing, 2010.

ROCHA, Suzana. Ameliorer l'accompagnement dans les partenariats de teletandem francobresiliens. 2009. Dissertação (Mestrado em Arts, Lettres, Langues, Communication) - Université Charles-de-Gaulle, Lille III, France, 2009.

SALOMÃO, Ana Cristina B. Gerenciamento e estratégias pedagógicas na mediação dos pares no teletandem e seus reflexos para as práticas pedagógicas dos interagentes. 2008 Dissertação (Mestrado em Estudos Linguísticos) UNESP/IBILCE, São José do Rio Preto, 2008. 
SANTOS, Gerson R. Características da interação no contexto de aprendizagem in-tandem. 2008. Dissertação (Metrado em Estudos Linguísticos) UNESP/IBILCE, São José do Rio Preto, 2008.

SILVA, Tomáz Tadeu da. (Org.). Identidade e diferença: a perspectiva dos estudos culturais. São Paulo: Vozes, 2000.

SILVA, Tomáz Tadeu da. (Org.); HALL, S.; WOODWARD, K. Identidade e diferença: a perspectiva dos estudos culturais. 5. ed. São Paulo: Vozes, 2000. SILVA, Tomáz Tadeu da. Documentos de identidade: uma introdução às teorias do currículo. Belo Horizonte: Autêntica, 2007.

TELLES, João Antonio; VASSALLO, Maria Luisa. Foreign language learning in-tandem: teletandem as an alternative proposal in CALLT1. The ESPecialist, v. 27, n. 2, p. 189-212, 2006.

TELLES, João Antonio (Org.). Teletandem: um contexto virtual, autônomo e colaborativo de aprendizagem de línguas estrangeiras para o século XXI. Campinas: Pontes, 2009.

VASSALLO, Maria Luisa; TELLES, João Antonio. Foreign language learning in-tandem: theoretical principles and research perspectives. The ESPecialist, v. 27, n. 1, p. 83-118, 2006.

VASSALLO, Maria Luisa. Relações de poder em parcerias de teletandem. 2010. Tese (Doutorado em Estudos Linguísticos) - UNESP, São José do Rio Preto/Università Ca’Foscari, Venezia, 2010.

WELSCH, Wolfgang. Transculturality: the puzzling form of cultures today. California Sociologist, v. 17-18, p. 19-39, 1994.

WOLFF,Juergen.TANDEMadrid: du hilfst mir lernen, ich helfe dir lernen, und so verstehen wir uns besser. Spracharbeit, v. 1, n. 21-26; Hispanorama, v. 32, p. 13-18, 1982. 